\title{
BMJ Open Epidemiological characterisation of asymptomatic carriers of COVID-19 in Colombia: a cross-sectional study
}

Aníbal A. Teherán (10 , ${ }^{1,2}$ Gabriel Camero Ramos, ${ }^{3}$ Ronald Prado de la Guardia, ${ }^{3}$ Carolina Hernández, ${ }^{2}$ Giovanny Herrera, ${ }^{2}$ Luis M Pombo, ${ }^{1}$ Albert Alejandro Avila,,${ }^{3,4}$ Carolina Flórez, ${ }^{5}$ Esther C Barros, ${ }^{5}$ Luis Perez-Garcia, ${ }^{2}$ Alberto Paniz-Mondolfi, ${ }^{6}$ Juan David Ramírez (1) ${ }^{2}$

To cite: Teherán AA, Camero Ramos G, Prado de la Guardia R, et al. Epidemiological characterisation of asymptomatic carriers of COVID-19 in Colombia: a crosssectional study. BMJ Open 2020;10:e042122. doi:10.1136/ bmjopen-2020-042122

- Prepublication history and additional material for this paper is available online. To view these files, please visit the journal online (http://dx.doi.org/10. 1136/bmjopen-2020-042122).

Received 27 June 2020 Revised 14 November 2020 Accepted 23 November 2020
Check for updates

(C) Author(s) (or their employer(s)) 2020. Re-use permitted under CC BY-NC. No commercial re-use. See rights and permissions. Published by BMJ.

For numbered affiliations see end of article.

Correspondence to Dr Juan David Ramírez; juand.ramirez@urosario.edu.co

\section{ABSTRACT}

Introduction Asymptomatic carriers (AC) of the new SARS-CoV-2 represent an important source of spread for COVID-19. Early diagnosis of these cases is a powerful tool to control the pandemic. Our objective was to characterise patients with AC status and identify associated sociodemographic factors.

Methods Using a cross-sectional design and the national database of daily occurrence of COVID-19, we characterised both socially and demographically all ACs. Additional correspondence analysis and logistic regression model were performed to identify characteristics associated with $\mathrm{AC}$ state $(\mathrm{OR}, 95 \% \mathrm{Cl})$.

Results $76.162 \mathrm{ACs}(12.1 \%$; $95 \% \mathrm{Cl} 12.0 \%$ to $12.2 \%)$ were identified, mainly before epidemiological week 35 . Age $\leq 26$ years $(1.18 ; 1.09$ to 1.28$)$, male $\operatorname{sex}(1.51 ; 1.40$ to 1.62), cases imported from Venezuela, Argentina, Brazil, Germany, Puerto Rico, Spain, USA or Mexico (12.6; 3.03 to 52.5) and autochthonous cases (22.6; 5.62 to 91.4) increased the risk of identifying ACs. We also identified groups of departments with moderate $(1.23 ; 1.13$ to 1.34$)$ and strong (19.8; 18.6 to 21.0) association with ACs. Conclusion Sociodemographic characteristics strongly associated with $\mathrm{AC}$ were identified, which may explain its epidemiological relevance and usefulness to optimise mass screening strategies and prevent person-to-person transmission.

\section{INTRODUCTION}

In 6 March 2020, Colombia reported the first case of COVID-19, and as of 22 September more than 700000 cases have been confirmed nationwide. ${ }^{1}$ Asymptomatic carriers (AC) may be associated with the accelerated growth of cases in the initial phases of the pandemic, inadvertently spreading the infection to close contacts. In this case, transmission can only be limited until a diagnosis of SARS-CoV-2 infection is rendered after (1) isolation due to symptom onset, (2) contact tracing or (3) identification during massive screening strategies. $^{23}$

AC and presymptomatic cases are epidemiologically relevant since they represent a silent

\section{Strengths and limitations of this study}

- Cross-sectional studies are useful to identify possible variables associated with asymptomatic carriers (ACs).

- Weekly surveillance of potential cases reduced selection and classification bias of ACs.

- The large number of COVID-19 ACs included in this study allowed to draw precise estimates.

- The ongoing epidemic phase of COVID-19 in Colombia decreases the uncertainty of invisible subgroup occurrences.

- Estimates and characteristics associated with ACs may improve epidemiological surveillance in other countries.

source of spread in various public settings (eg, public transportation, emergency rooms, supermarkets, shelters).$^{4-6}$ The proportion of ACs has been estimated at $15 \%-25 \%$, but seroprevalence studies have reported values of up to $43.2 \%$ (95\% CI $32.2 \%$ to $54.7 \%$ ). Nonetheless, many presymptomatic patients are wrongfully classified as ACs during the incubation phase; to later become paucisymptomatic or develop respiratory manifestations ranging from pneumonia to respiratory failure, or exhibit any other clinical symptoms within the COVID-19 spectrum. ${ }^{4-8}$

Epidemiological predictive models have been developed and updated to incorporate silent mobility through AC phenotype in anticipation for the second and third epidemic waves of COVID-19. Such is the case for the Susceptible, Exposed, Infected and Recovered (SEIR) model, recently updated to Susceptible, Exposed, Asymptomatic, Infected and Recovered. ${ }^{9}$ In China, estimates indicate that $60 \%-65 \%$ of ACs remained undetected. Therefore, under the SEIR model and applying machine-learningbased transmission simulators, including 
the number of undetected AC within its parameters and assuming 15 close contacts per day, estimates suggest that as of 15 April 2020, the USA-the country contributing the majority of cases imported to Colombia-could have presented 277 641-495 128 latent cases of COVID-19, potentially increasing the spread of the virus. ${ }^{10}$

The assessment of ACs and the identification of sociodemographic characteristics associated with this subpopulation could be useful to estimate sample calculations in massive screening studies, as well as adjust control and mitigation measures-especially the intensity of isolation. Therefore, the objective of our study was to characterise ACs demographically and socially, as well as to identify individual characteristics in interaction models associated with ACs.

\section{METHODOLOGY}

\section{Design and data selection}

We performed a cross-sectional study with information from the National Institute of Health (INS) database on COVID-19 cases updated until 31 August 2020 (https:// www.ins.gov.co/Noticias/Paginas/coronavirus-casos. aspx). By INS protocol, suspected AC cases remained in quarantine for 7 days while monitoring the appearance of symptoms on a daily basis; on the eighth day, a nasal swab sample was collected to identify or rule out AC state. Records without health status information (symptomatic, asymptomatic) were excluded. The database is public, with deidentified patient data and IRB approval was thus exempt.

\section{Patient and public involvement statement}

This research was done without patient involvement. Patients were not invited to comment on the study design and were not consulted to develop patient relevant outcomes or interpret the results. Patients were not invited to contribute to the writing or editing of this document for readability or accuracy.

\section{Database and variables}

We used variables such as date of diagnosis, age, sex, country of origin, department, case type (imported, related), care setting (home, nursing home, hospital, intensive care unit) and outcome (recovered, convalescent, deceased). The date of diagnosis was adjusted into epidemiological weeks (EW), which were later grouped according to the pattern of AC occurrence (online supplemental figure S1) in EW 10-34, $\geq 35$; additionally, the variable AC (yes, no) was established.

\section{Statistical analysis}

Data are presented in medians or proportions estimated with $95 \%$ CI due to the lack of massive screening for COVID-19 in certain areas of the country; additionally, we estimated AC rates per 100000 population by departments using Colombian demographic estimates for 2020 from the National Administrative Department of
Statistics (DANE). The geographical origin and destination of imported cases were represented with a Sankey Plot (SankeyMATIC (BETA)). Cumulative trends and case charts were created with the number of daily cases by Epid_weeks (RStudio V.1.2.5042). In addition, a heatmap analysis was included to depict a dynamic representation of daily cases by Department from 6 March through 3 August 2020 (Orange Data Mining \& Fruitful Fun, V.3.25). The proportion of asymptomatic and symptomatic patients and the median age were compared with the $\mathrm{Z}$ and $\mathrm{U}$ Mann-Whitney tests, respectively (significant $\mathrm{p}$ value $<0.05$, two tails; Addinsoft. 2020. XLSTAT statistical and data analysis solution. New York, USA. https://www. xlstat.com). Age was dichotomised between $0-26$ and $\geq 27$ years due to its association with asymptomatic and symptomatic states, respectively (preliminary exploratory analysis not shown).

Countries of origin and departments associated with ACs were identified, respectively, with a correspondence analysis (CA) and factorial analysis of mixed data using PCAmix. Raw data were used for CA while symptomatic and AC rates per 100000 population were used for PCAmix . Additionally, with principal coordinates (PC) obtained with both CA (PC-CA) and PCAmix (PC-PCAmix), groups with a variable level of association with ACs were created (Addinsoft. 2020. XLSTAT statistical and data analysis solution. New York, USA. https://www. xlstat.com).

To estimate the association between sociodemographic characteristics with ACs (OR 95\%), two logistic regression models (LRM) were performed, the first to establish the main effects and the second a step-backward interaction model of the second level ( $p$ value in $<0.05$; $p$-value out: $>0.1$ ), which used the lowest Akaike criteria to select the best model (JASP Team (2020). JASP (V.0.12.2))

\section{RESULTS}

\section{General characteristics}

We identified 76162 ACs (12.1\%; 12.0\%-12.2\%) out of 626887 cases reported in the database. Four cases were excluded due to lack of health status information. The occurrence of AC state in relation to symptomatic presented a continuous growth phase between EW 10 and 17 , and a peak at EW 18, followed by a newly increase between EW 19 and 34, and a steady state after EW 34 (figure $1 \mathrm{~A}$ and $\mathrm{B}$, online supplemental figure S1). Daily cases ranged from 1 to 4386 per day, and EW 34 registered the highest number of cases per day: 4141 and 4386.

Additionally, we report department clusters with a high occurrence of daily COVID-19 cases, which follow different dynamic patterns for ACs and symptomatic patients (figure 1C,D).

Throughout April, AC reports in Meta and Amazonas peaked; in May they peaked in Cartagena, Antioquia and Bogota, with Bogota's peak lasting until August 31st; in June-July, AC cases peaked in Atlantico, Barranquilla and Cordoba; and in August, they peaked in Santander 
A.

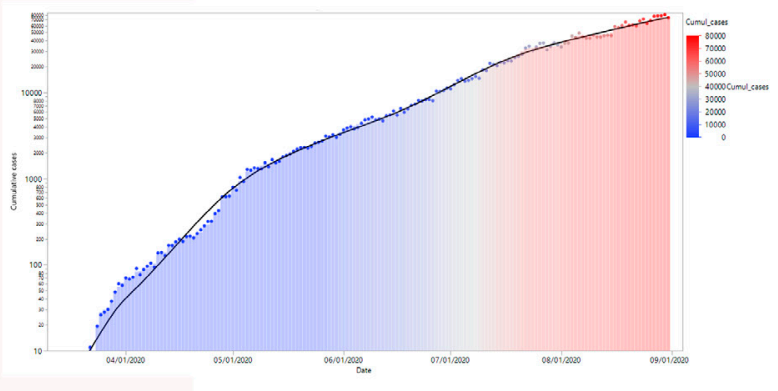

B.

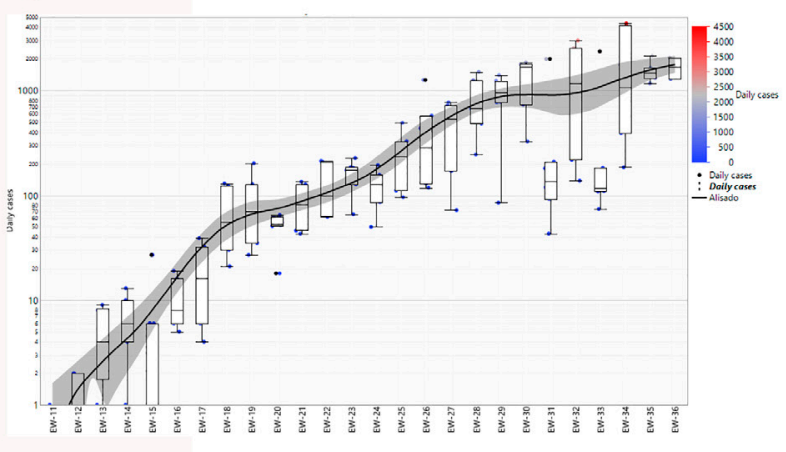

c.

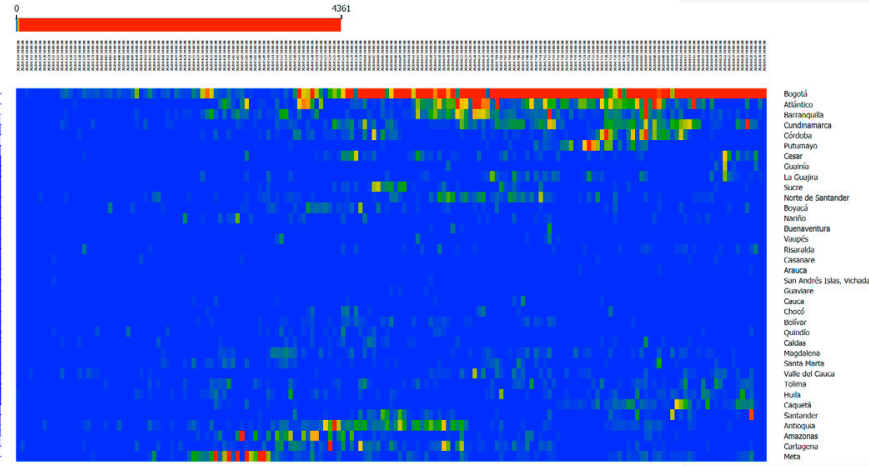

D.

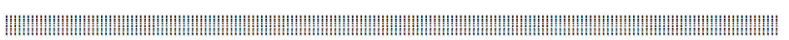

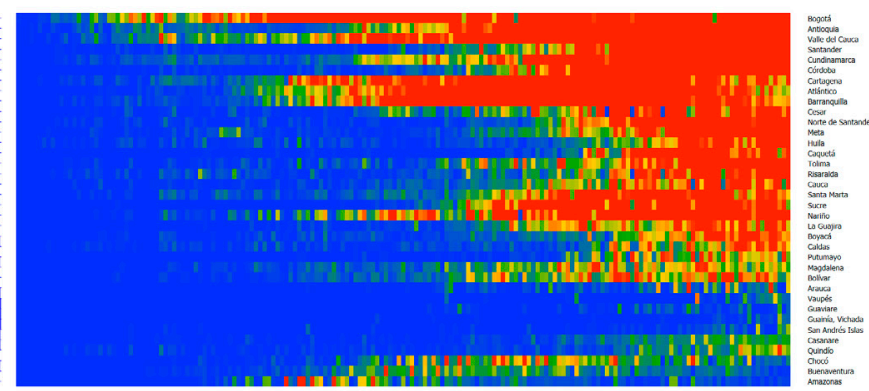

Figure 1 Daily accumulation and distribution of asymptomatic carriers (AC) by epidemiological week in Colombia. (A) The yaxis represents the number of cumulative ACs transformed into a base 10 logarithm. The number of cumulative cases per day is located in points that increase in colour intensity according to the occurrence of cases. (B) The y-axis represents the number of daily ACs transformed into a base 10 logarithm. The number of daily cases per day is located in boxplots. (C) Heatmap showcasing the number of ACs (top) and (B) symptomatic patients (bottom) diagnosed in every Colombian department until 31 August 2020.

and Cundinamarca. Overall, the frequency of ACs in Colombia has followed a dichotomic trend as shown in the lateral cluster of figure 1C: AC occurrences are distributed between the highly frequent profile in Bogota during most of the epidemic and the intermittent peak occurrences of the rest of Colombian departments.

More than half of the imported ACs came from Europe, specifically Spain, followed by North and South America. Those that arrived from Spain and USA were distributed mainly in Bogotá, Cundinamarca, Antioquia and Valle del Cauca. Amazonas department only received imported ACs from South American countries. The origin and distribution of imported symptomatic patients were more diverse; however, most cases originated from Spain, USA, Ecuador, Mexico, Brazil, or Panama, and were mainly distributed across Bogotá, Antioquia and Valle del Cauca (figure 2).

More than $90 \%$ of ACs were located in Bogotá, Atlantico and Meta. However, Bogota, Amazonas and Putumayo reported the highest $\mathrm{AC}$ rates per 100000 population (table 1, online supplemental table S1). Median age was 37 years old, lower than the symptomatic patients. Most of them were males (table 1). By 31 August, most ACs were classified as recovered $(85.8 \% ; 85.6 \%$ to $86.1 \%)$ or in domiciliary isolation $(13.6 \% ; 13.4 \%$ to $13.8 \%)$, and 356 patients $(0.46 \% ; 0.42 \%$ to $0.52 \%)$ were diagnosed during their stay in ICUs (80 patients), general hospitalisation services (185 patients) or in postmortem phase (91 deceased). These 356 cases may have been treated for symptoms unrelated to COVID-19 or perhaps RT-PCR results arrived late, with some arriving even after the patient had already passed away.

\section{Factors associated with $\mathrm{AC}$ condition}

Using the PC-CA and PC-PCAmix, a group of six countries and three groups of departments were associated with AC state (figure 3). To execute LRMs, the variables 'age group 0-26 years' and 'male sex' were transformed into dummi $(0 / 1)$. With a preliminary LRM, a higher $\beta$ coefficient was estimated in relation to cases imported from countries associated with ACs; therefore, the variable 'geographical origin' was created, composed of the categories 'imported from countries associated with symptomatic' (imported CAS—referent), 'imported from countries associated with ACs' (imported CA-ACs) and 'related cases'. Additionally, a variable was created for the departments grouped with the PCAmix (departments with low association-referent) and for the EW (EW 10-34-referent). The first LRM (main effects) identified a significant association of all index sociodemographic categories with ACs state (online supplemental table S2). The second model explores the following interactions: 
A

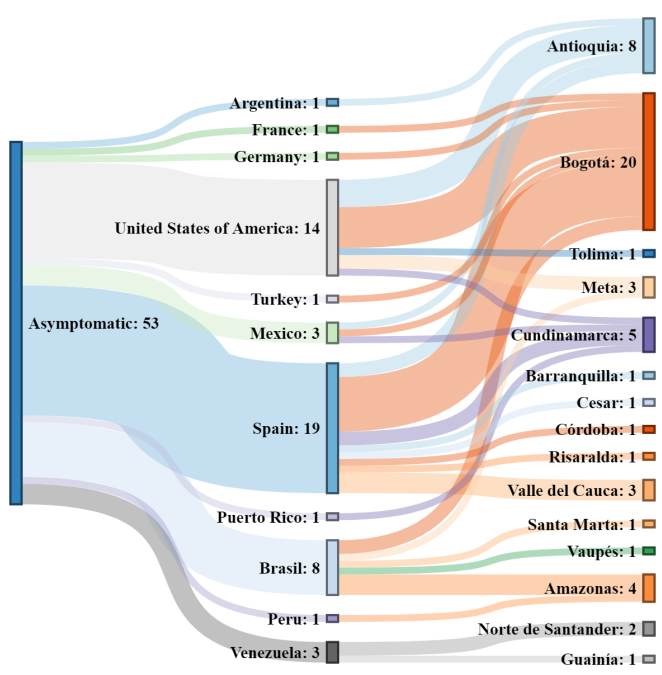

B

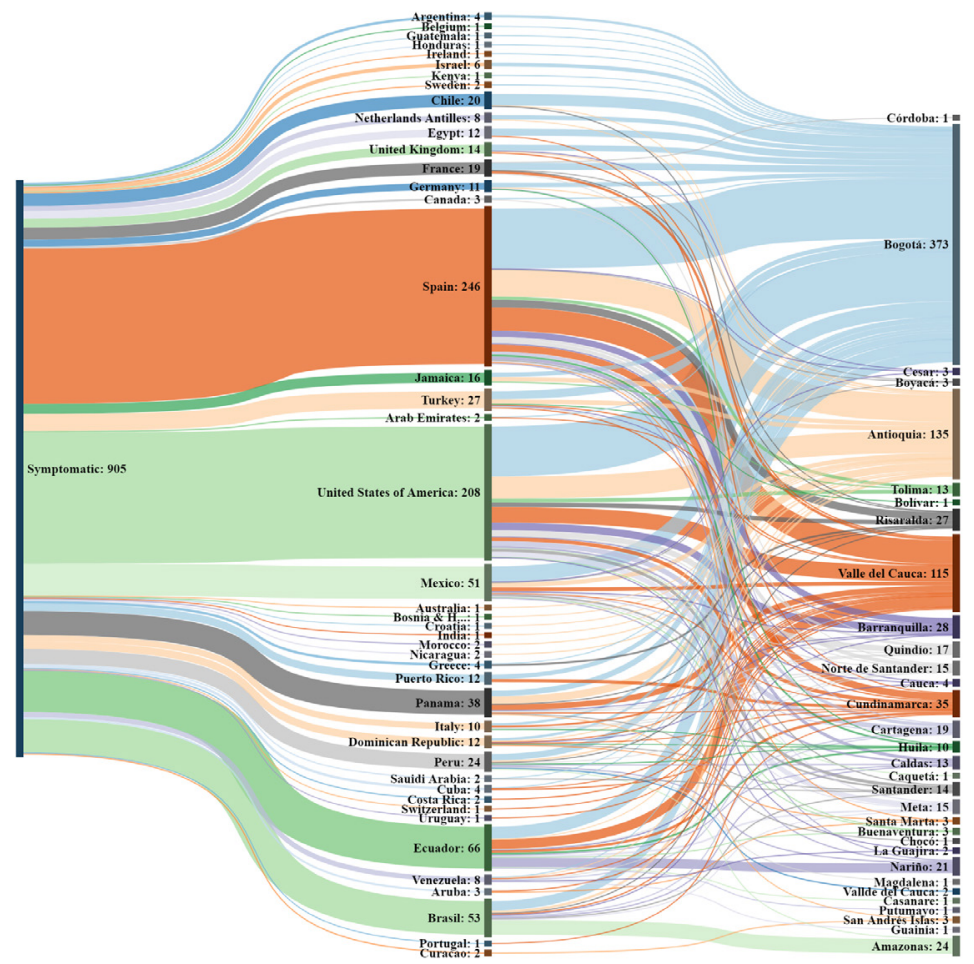

Figure 2 Origin and destination of imported asymptomatic and symptomatic cases. The left and right figures, respectively, represent the country of origin and destination department of asymptomatic carriers (AC) and symptomatic patients. The thickness of the link tapes corresponds to the number of reported cases.

(1) geographical origin and grouped departments, (2) geographical origin and EW, (3) age group (0-26 years) and gender, (4) grouped departments and gender; and (5) age (0-26 years) and EW. We identified interactions between the variables 'gender' (males), 'age' (0-26 years), and 'EW' and the grouped departments; and between the variables 'gender' (males) and 'age' (0-26 years; table 2$)$.

Variables 'age' (0-26 years), 'gender' (male), 'departments with moderate or strong association', 'imported CA-ACs' and 'related cases' were found to increase the risk of identifying ACs state. It was also determined that the risk increased for males (0-26 years), especially for those located in departments with a strong or moderate association since EW 35. However, it should be noted that the risk of identifying ACs has decreased since EW 35 when only taking isolated estimates into account (table 2).

As this is a cross-sectional study, the Strengthening the Reporting of Observational Studiesin Epidemiology checklist was followed and can be revised in online supplemental table S3.

\section{DISCUSSION}

We found that, in an isolated fashion, age $<27$ years old, imported cases from a group of 6 countries, autochthonous cases and the occurrence in groupings of departments were associated with AC state. Additionally, the risk of being a male AC was only identified in departments with moderate or strong risk, and the risk was variable in the groupings of departments throughout specific epidemiological periods.

Additionally, our results show that the proportion of ACs in Colombia lays between $12 \%$ and $12.2 \%$ (table 1), a lower estimate than previously described in other case series or mass screening studies with reported proportions between $5 \%$ and $80 \% .{ }^{11-14}$ Given the inclusion of presymptomatic patients or the unification of AC with non-critical symptoms in some reports, we cannot rule out that a non-differential classification bias influenced these estimates. An adapted definition for AC in Colombia may address this limitation.

Figure 1 shows that the majority of imported cases to Colombia came from Spain and USA, where AC rates have been estimated at $2.5 \%$ and $25 \%$, respectively. ${ }^{14} 15$ Although imported cases carry a distinctive genetic load that, populationwise, could manifest itself as a particular phenotype, ${ }^{16}$ currently there are no reports of genetic variants associated with $\mathrm{AC}$ in general or for any of the four AC subtypes described in the literature. ${ }^{17}$ Subsequent research should be conducted on the possible association between ACs and phylogenetic variants (or other variables) to support the differential risk identified in imported cases from different regions of the world.

We identified that imported cases from a group of six countries were strongly associated with AC (figure 2, online supplemental file 2, table 2), and although no interaction was established between the country of import 


\begin{tabular}{|c|c|c|c|}
\hline \multirow[b]{2}{*}{ Variables } & \multirow{2}{*}{$\begin{array}{l}\text { Asymptomatic } \\
\mathrm{N}: 76162\end{array}$} & \multirow{2}{*}{$\begin{array}{l}\text { Symptomatic } \\
\text { N: } 550725\end{array}$} & \multirow[b]{2}{*}{$P$ value } \\
\hline & & & \\
\hline Age, years & $35(25-49)$ & $37(27-52)$ & $<0.001$ \\
\hline $0-26$ & $21310(27.9)$ & $129529(23.5)$ & $<0.001$ \\
\hline$\geq 27$ & $54852(72.0)$ & 421196 (76.4) & $<0.001$ \\
\hline \multicolumn{4}{|l|}{ Sex } \\
\hline Male & 38836 (50.9) & 283068 (51.4) & 0.035 \\
\hline Female & 37326 (49.0) & 267657 (48.6) & 0.035 \\
\hline \multicolumn{4}{|c|}{ Geographical source } \\
\hline Related* & 76108 (99.9) & 549789 (99.8) & $<0.001$ \\
\hline Imported & $54(0.07)$ & $936(0.170)$ & $<0.001$ \\
\hline \multicolumn{4}{|l|}{ Departments $†$} \\
\hline Bogotá & $68143(89.4)$ & 148258 (26.9) & $<0.001$ \\
\hline Atlántico & 1455 (1.91) & 26059 (4.73) & $<0.001$ \\
\hline Meta & $836(1.10)$ & $8532(1.55)$ & $<0.001$ \\
\hline Barranquilla & $737(0.97)$ & 34262 (6.22) & $<0.001$ \\
\hline Cundinamarca & $690(0.91)$ & 23222 (4.22) & $<0.001$ \\
\hline Imported casesł & 53 & 905 & 958 \\
\hline Spain & $19(35.8)$ & 246 (27.2) & 0.170 \\
\hline USA & $14(26.4)$ & 208 (22.9) & 0.565 \\
\hline Brazil & $8(15.1)$ & $53(5.86)$ & 0.007 \\
\hline Mexico & $3(5.66)$ & $51(5.64)$ & 0.994 \\
\hline Venezuela & $3(5.66)$ & $8(0.88)$ & 0.002 \\
\hline Argentina & $1(1.89)$ & $4(0.44)$ & 0.156 \\
\hline France & $1(1.89)$ & $19(2.10)$ & 0.916 \\
\hline Germany & $1(1.89)$ & $11(1.22)$ & 0.669 \\
\hline Peru & $1(1.89)$ & $24(2.65)$ & 0.734 \\
\hline Puerto Rico & $1(1.89)$ & $12(1.33)$ & 0.732 \\
\hline Turkey & $1(1.89)$ & 27 (2.98) & 0.645 \\
\hline Unknow & 1 & 31 & NA \\
\hline
\end{tabular}

${ }^{*}$ Cases that appeared spontaneously in Colombia.

†Top 5 of the departments with the highest frequency of asymptomatic carriers.

¥The total number of imported asymptomatic and symptomatic cases was used as the denominator to estimate proportions by country of origin.

NA, Not applicable.

and the destination department (data not shown), we observed that departments strongly associated with AC had less diversity of import origin. Such is the case of Meta and Amazonas, which exclusively imported cases from USA and Brazil/Peru, respectively (figure 2).

Among the demographic characteristics, the association between $\mathrm{AC}$ state and patients under 27 years of age stands out. Possible explanations for this observation include: (1) the lower presence of comorbid conditions and baseline health issues within this age group and (2) the higher risk of exposure through work activities which are greater in this age group. ${ }^{18}$ However, clinical or social environment could also explain this finding, as a study in skilled nursing facility residents showed a high proportion of AC in those over 70 years of age; however, this was a premature finding since most patients were later reclassified as presymptomatic or paucisymptomatic. ${ }^{11}$

We identified a higher frequency of men infected with COVID-19 consistent with reports from other countries around the world, except in Spain and Switzerland, where women ranked first. ${ }^{19}$ Frequent occupations performed by men, as well as certain immunological and genetically susceptible backgrounds have been associated with this finding. ${ }^{19}{ }^{20}$ In particular, the risk of being an $\mathrm{AC}$ was higher in men, and increased in geographical areas associated with AC. This interaction is not uncommon given that professions regularly carried out by men, including those such as taxi driving, private security or prison guarding, among other work settings, can be distributed asymmetrically within countries, a pattern that would explain our findings. ${ }^{20}$

The phases on the occurrence of cases throughout EWs and the interaction with groupings within departments associated with $\mathrm{AC}$ have been previously described in Chongqing, China, where researchers identified significant changes in the frequency of cases after implementation of geographical isolation measures. The dynamic changes in the detection and distribution of ACs throughout EWs could be explained by the surveillance strategy executed in Colombia kwon as 'PRASS' (in Spanish, tests, surveillance, and sustainable selective isolations); this can be particularly observed from EW 30 onwards (online supplemental figure S1) ${ }^{21}$ In Wuhan, a study showed that one group of ACs was linked to imported cases while others were linked mostly to autochthonous cases from geographically isolated areas of Wuhan. ${ }^{22}$ We identified that in addition to being associated with a travel history to foreign countries, ACs were also associated with cases that appear spontaneously (related), occurring differentially as measures of geographical and social isolation were applied.

The lack of mass screening for COVID-19 in Colombia is the main limitation of our study since the actual AC ratio and the distribution of specific characteristics may differ from those estimated in this report. On the other hand, although a cross-sectional design is not ideal to identify risk factors, to the best of our knowledge this is the first study aimed at identifying factors associated with AC state with population data unbiased by the inclusion of pre-symptomatic cases. ${ }^{23}$

The COVID-19 pandemic has had serious socioeconomic implications, including a collapse of healthcare systems, bankruptcy of companies as well as increasing trends in unemployment and crime rates. ${ }^{24-27}$ This has forced countries with limited resources-such as Colombia-to perform massive screenings in order to prematurely lift quarantine and isolation measures despite the latent risk of successive outbreaks caused by a potential silent spread of COVID-19 through cases in the presymptomatic phase or AC state. ${ }^{28} 29$ 
A

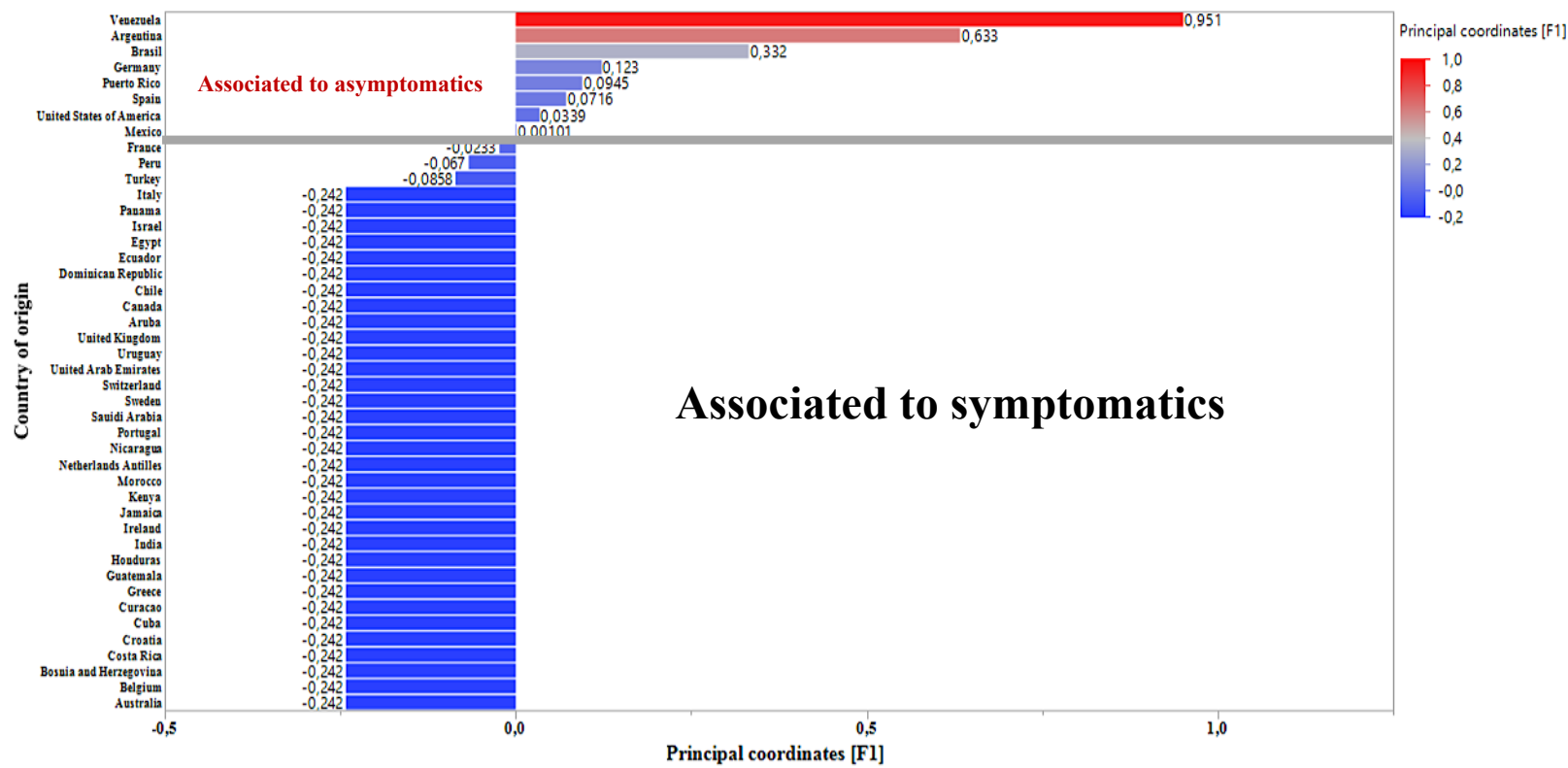

B

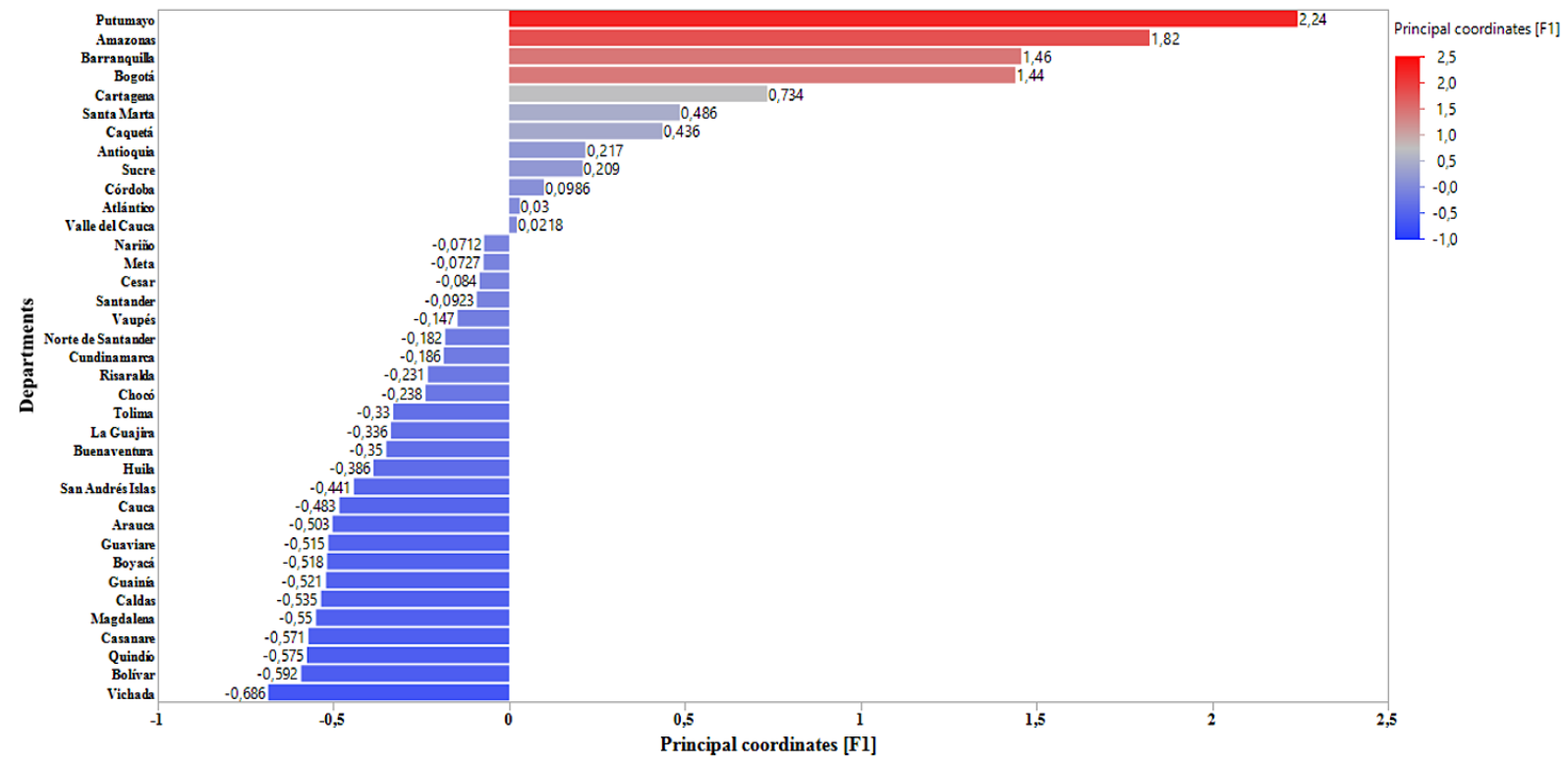

Figure 3 Groups of countries and departments associated with asymptomatic carrier (AC) state.(A) shows the group of countries associated with AC state identified with positive values of associated to asymptomatics. (B) shows departments grouped according to three intervals of CCC-CA: low association (CCC-CA: negative values), moderate association (CCC-CA: $>0-<0.05$ ), and strong association (CCC-CA: $\geq 0.5)$.

ACs transmit COVID-19 more efficiently than symptomatic patients for up to 21 days after the presumed date of infection. ${ }^{30} 31$ This led to their inclusion in mathematical models intended to estimate the probability or expected number of person-to-person infections on repatriation trips from Wuhan, China. ${ }^{732}$ Since then, ACs have become the target of mass screening in Asian and European countries effectively reducing economical losses due to unnecessary hospital care, controlling the spread in public or in-hospital settings, and allowing the execution of safe plans of social and work reintegration after quarantine and isolation. ${ }^{2833-37}$
To date, testing of asymptomatic individuals' rests at the discretion of physicians when justified on a case-by-case basis. On the other hand, the utility of SARS-CoV-2 testing for broad screening of asymptomatic individuals remains to be determined given the limited sensitivity data available for most commercially available test kits. ${ }^{38}$

\section{CONCLUSION}

Together, our findings demonstrate sociodemographic trends strongly associated with COVID-19 AC state in Colombia at a departmental and national level. We 
Table 2 Factors associated with asymptomatic carrier (AC) state in Colombia

\begin{tabular}{|c|c|c|c|}
\hline \multirow[b]{2}{*}{ Variable } & \multicolumn{3}{|c|}{ Interaction model } \\
\hline & $\boldsymbol{\beta}$ & OR (95\% Cl) & $P$ value \\
\hline Intercept & -7.316 & - & $<0.001$ \\
\hline$>26$ years & Ref. & - & - \\
\hline 0-26 years & 0.172 & 1.188 (1.096 to 1.287$)$ & $<0.001$ \\
\hline \multicolumn{4}{|l|}{ Sex } \\
\hline Female & Ref. & - & - \\
\hline Male & 0.414 & $1.513(1.408$ to 1.625$)$ & $<0.001$ \\
\hline \multicolumn{4}{|l|}{ Department } \\
\hline Low association (1) & Ref. & - & - \\
\hline Moderate association (2) & 0.211 & $1.234(1.137$ to 1.340$)$ & $<0.001$ \\
\hline \multicolumn{4}{|l|}{ Geographical source } \\
\hline Imported CA-AC† (1) & 2.536 & 12.62 (3.034 to 52.54) & $<0.001$ \\
\hline Related cases $\ddagger$ (2) & 3.121 & 22.67 (5.620 to 91.47$)$ & $<0.001$ \\
\hline \multicolumn{4}{|l|}{ EW } \\
\hline $10-34$ & Ref. & - & \\
\hline$\geq 35$ & -1.008 & $0.365(0.320$ to 0.415$)$ & $<0.001$ \\
\hline $0-26$ years+male & 0.047 & 1.048 (1.010 to 1.089$)$ & 0.014 \\
\hline 0-26 years+department (2) & 0.174 & 1.190 (1.069 to 1.325$)$ & 0.001 \\
\hline 0-26 years+department (3) & -0.005 & 0.995 (0.919 to 1.077) & 0.898 \\
\hline
\end{tabular}

${ }^{*} \mathrm{CAS}$ countries associated with symptomatic patients.

†CA-AC countries associated with AC.

$\ddagger$ Spontaneous cases.

EW, epidemiological weeks; .

believe that the implementation of massive screening campaigns to detect AC and presymptomatic patients is paramount to further characterise this phenomenon and adequately guide public health measures of containment and prevention. Additional molecular analysis of viral and host genotypic characteristics should be conducted to determine possible associations with AC state.

\section{Author affiliations}

${ }^{1}$ Grupo de investigación COMPLEXUS, Fundación Universitaria Juan N Corpas, Bogotá, Colombia

${ }^{2}$ Grupo de Investigaciones Microbiológicas-UR (GIMUR), Departamento de Biología, Facultad de Ciencias Naturales, Universidad del Rosario, Bogotá, Colombia

${ }^{3}$ Cruz Roja Colombiana Seccional Cundinamarca-Bogotá, Bogota, Colombia ${ }^{4}$ Hospital Simon Bolívar, Bogotá, Colombia

${ }^{5}$ Instituto Nacional de Salud, Bogotá, Colombia

${ }^{6}$ Icahn School of Medicine at Mount Sinai, New York, New York, USA

Contributors AAT, AP-M and JR designed the study. AAT, GC, RPdIG, CH, GH, LMP, LP-G and AA conducted the statistical and descriptive analyses. CF, ECB provided the data for the analysis. AAT, AP-M, LP-G and JR drafted the manuscript. All authors approved the final version of the manuscript.

Funding The authors have not declared a specific grant for this research from any funding agency in the public, commercial or not-for-profit sectors.

Competing interests None declared.

Patient consent for publication Not required.

Provenance and peer review Not commissioned; externally peer reviewed.

Data availability statement Data are available in a public, open access repository. All data relevant to the study are included in the article or uploaded as supplementary information. Data is freely available from the National Institute of Health (INS) database on COVID-19 cases updated until August 31, 2020 (https:// www.ins.gov.co/Noticias/Paginas/coronavirus-casos.aspx).

Supplemental material This content has been supplied by the author(s). It has not been vetted by BMJ Publishing Group Limited (BMJ) and may not have been peer-reviewed. Any opinions or recommendations discussed are solely those of the author(s) and are not endorsed by BMJ. BMJ disclaims all liability and responsibility arising from any reliance placed on the content. Where the content includes any translated material, BMJ does not warrant the accuracy and reliability of the translations (including but not limited to local regulations, clinical guidelines, 
terminology, drug names and drug dosages), and is not responsible for any error and/or omissions arising from translation and adaptation or otherwise.

Open access This is an open access article distributed in accordance with the Creative Commons Attribution Non Commercial (CC BY-NC 4.0) license, which permits others to distribute, remix, adapt, build upon this work non-commercially, and license their derivative works on different terms, provided the original work is properly cited, appropriate credit is given, any changes made indicated, and the use is non-commercial. See: http://creativecommons.org/licenses/by-nc/4.0/.

ORCID iDs

Aníbal A. Teherán http://orcid.org/0000-0002-7666-8766

Juan David Ramírez http://orcid.org/0000-0002-1344-9312

\section{REFERENCES}

1 Ins.gov. Coronavirus en Colombia. Available: https://www.ins.gov.co/ Noticias/Paginas/Coronavirus.aspx [Accessed 10 May 2020].

2 Rudan I. A cascade of causes that led to the COVID-19 tragedy in Italy and in other European Union co1. Rudan I. A cascade of causes that led to the COVID-19 tragedy in Italy and in other European Union countries. J Glob Health 2020;10:10335.

3 Yi Y, Lagniton PNP, Ye S, et al. COVID-19: what has been learned and to be learned about the novel coronavirus disease. Int J Biol Sci 2020;16:1753-66.

4 Tindale L, Coombe M, Stockdale JE, et al. Transmission interval estimates suggest pre-symptomatic spread of COVID-19. medRxiv 2020:2020.03.03.20029983.

5 Zhang W. Estimating the presymptomatic transmission of COVID19 using incubation period and serial interval data. medRxiv 2020.

6 Rahimi F, Talebi Bezmin Abadi A. Challenges of managing the asymptomatic carriers of SARS-CoV-2. Travel Med Infect Dis 2020;37:101677.

7 Teherán AA, Camero G, Prado R, et al. Presumptive asymptomatic COVID-19 carriers' estimation and expected person-to-person spreading among repatriated passengers returning from China. Travel Med Infect Dis 2020;37:101688.

8 Lavezzo E, Franchin E, Ciavarella C, et al. Suppression of COVID-19 outbreak in the municipality of VO, Italy. medRxiv 2020.

9 Oliveira G. Refined compartmental models, asymptomatic carriers and COVID-19. medRxiv 2020.

10 Yu Y, Liu Y-R, Luo F-M, et al. COVID-19 asymptomatic infection estimation. medRxiv 2020.

11 Arons MM, Hatfield KM, Reddy SC, et al. Presymptomatic SARSCoV-2 infections and transmission in a skilled nursing facility. $N$ Engl J Med 2020;382:2081-90.

12 Wong J, Abdul Aziz ABZ, Chaw L, et al. High proportion of asymptomatic and presymptomatic COVID-19 infections in travelers and returning residents to Brunei. J Travel Med 2020.

13 Hijnen D, Marzano AV, Eyerich K, et al. SARS-CoV-2 transmission from presymptomatic meeting Attendee, Germany. Emerg Infect Dis 2020;26:1935-7.

14 CEBM. COVID-19: what proportion are asymptomatic? Available: https://www.cebm.net/covid-19/covid-19-what-proportion-areasymptomatic/ [Accessed 16 Jun 2020].

15 Ministerio de Sanidad C. Estudio Nacional de sero-Epidemiología de la Infección POR SARS-CoV-2 en España (ENE-Covid). Informe PRELIMINAR tras La primera ronda (13/05/2020). Gob España 2020.

16 Forster P, Forster L, Renfrew C, et al. Phylogenetic network analysis of SARS-CoV-2 genomes. Proc Natl Acad Sci U S A 2020.
17 Zhou X, Li Y, Li T, et al. Follow-Up of asymptomatic patients with SARS-CoV-2 infection. Clin Microbiol Infect 2020.

18 Yang R, Gui X, Xiong Y. Comparison of clinical characteristics of patients with asymptomatic vs symptomatic coronavirus disease 2019 in Wuhan, China. JAMA Netw Open 2020;3:e2010182.

19 Márquez EJ, Trowbridge J, Kuchel GA, et al. The lethal sex gap: COVID-19. Immun Ageing 2020;17:13.

20 Koh D. Occupational risks for COVID-19 infection. Occup Med 2020;70:3-5.

21 Instituto Nacional de Salud - Ministerio de Salud y Protección Social. Orientaciones para La Vigilancia en Salud Pública de la Covid19. ORIENTACIONES para La VIGILANCIA en SALUD PÚBLICA de Ia COVID-19. Colombia: Ins - Minsalud. Documento Técnico Científico, 2020.

22 Tao Y, Cheng P, Chen W, et al. High incidence of asymptomatic SARS-CoV-2 infection, Chongqing, China. SSRN Electron J 2020.

23 Sahu KK, Kumar R. Preventive and treatment strategies of COVID-19: from community to clinical trials. J Fam Med Prim Care 2020;9:2149-57.

24 Nussbaumer-Streit B, Mayr V, Dobrescu Al, et al. Quarantine alone or in combination with other public health measures to control COVID-19: a rapid review. Cochrane Database Syst Rev 2020;4:CD013574.

25 Nicola M, Alsafi Z, Sohrabi C, et al. The socio-economic implications of the coronavirus pandemic (COVID-19): a review. Int J Surg 2020;78:185-93.

26 Kalleberg AL, von WTM. The U.S. labor market during and after the great recession: continuities and transformations. RSF Russell Sage Found J Soc Sci 2017;3:1-19.

27 Sutherland M, McKenney M, Elkbuli A. Gun violence during COVID-19 pandemic: paradoxical trends in New York City, Chicago, Los Angeles and Baltimore. Am J Emerg Med 2020:j.ajem.2020.05. 006. doi:10.1016/j.ajem.2020.05.006

28 Gilbert M, Dewatripont M, Muraille E, et al. Preparing for a responsible lockdown exit strategy. Nat Med 2020;26:643-4.

29 World Health Organisation. Considerations in adjusting public health and social measures in the context of COVID-19. World Heal Organ 2020:1-7 https://www.who.int/publications-detail/risk-

30 Prather KA, Wang CC, Schooley RT. Reducing transmission of SARS-CoV-2. Science 2020;368:1422-4.

31 Huff HV, Singh A. Asymptomatic transmission during the COVID-19 pandemic and implications for public health strategies. Clin Infect Dis 2020:ciaa654. doi:10.1093/cid/ciaa654

3232 Gostic K, Gomez ACR, Mummah RO, et al. Estimated effectiveness of symptom and risk screening to prevent the spread of COVID-19. Franco E, Ferguson nm, McCaw JM, EDS. Elife 2020;9:e55570.

33 Peto J, Alwan NA, Godfrey KM, et al. Universal Weekly testing as the UK COVID-19 lockdown exit strategy. Lancet 2020;395:1420-1.

34 Mallapaty S. Will antibody tests for the coronavirus really change everything? Nature 2020;580:571-2.

35 The race against COVID-19. Nat Nanotechnol 2020;15:239-40.

36 Mark K, Steel K, Stevenson J, et al. Coronavirus disease (COVID-19) community testing team in Scotland: a 14-day review, 6 to 20 February 2020. Euro Surveill 2020;25.

37 Rosenthal PJ. The importance of diagnostic testing during a viral pandemic: early lessons from novel coronavirus disease (CoVID-19). Am J Trop Med Hyg 2020.

38 Woloshin S, Patel N, Kesselheim AS. False Negative Tests for SARS-CoV-2 Infection - Challenges and Implications. N Engl J Med 2020;383:e38. 